\title{
Features of Fine Iridium Powders Dissolution in Acidic Media
}

\author{
Roman V. Borisov*a,b, Oleg V. Belousov ${ }^{\mathrm{a}}$, \\ Ludmila I. Dorokhova ${ }^{a}$ and Anatoliy M. Zhizhaev ${ }^{a}$ \\ anstitute of Chemistry and Chemical Technology SB RAS \\ FRC "Krasnoyarsk Science Center SB RAS" \\ 50/24 Akademgorodok, Krasnoyarsk, 660036, Russia \\ ${ }^{b}$ Siberian Federal University \\ 79 Svobodny, Krasnoyarsk, 660041, Russia
}

Received 27.02.2017, received in revised form 09.05.2017, accepted 21.08.2017

The paper deals with the processes of dissolution of highly disperse iridium powders with sizes from $6 \mathrm{~nm}$ under hydrothermal conditions in hydrochloric acid solutions. Iridium powders with surface areas from 1 to $46 \mathrm{~m}^{2} / \mathrm{g}$ were synthesized in closed systems by reduction of aqueous solutions potassium hexachloroiridate(III). At temperatures from 170 to $195{ }^{\circ} \mathrm{C}$, the dissolution processes of iridium powders in solutions of hydrochloric acid with additives of oxidants were investigated. The data regarding to the degree of dissolution of iridium powders as a function of dispersion, temperature, time, oxidizer are obtained.

Keywords: iridium, nanopowders, hydrothermal synthesis, dissolution, autoclave technologies, temperature, solutions.

DOI: $10.17516 / 1998-2836-0029$.

(C) Siberian Federal University. All rights reserved

* Corresponding author E-mail address: roma_boris@list.ru 


\title{
Особенности растворения
}

\section{высокодисперсных порошков иридия \\ в кислых средах}

\author{
Р.В. Борисов ${ }^{\mathrm{a}, \tilde{\sigma}}$, О.В. Белоусов ${ }^{\mathrm{a}}$, \\ Л.И. Дорохова ${ }^{\text {, }, ~ А . М . ~ Ж и ж а е в ~}{ }^{\text {a }}$ \\ ${ }^{a}$ Институт химии и химической технологии СО РАН \\ ФИЦ «Красноярский научный иентр СО РАН» \\ Россия, 660036, Красноярск, Академгородок, 50/24 \\ ${ }^{6}$ Сибирский федеральный университет \\ Россия, 660041, Красноярск, пр. Свободньий, 79
}

В работе рассматриваются вопросы растворения высокодисперсных порошков иридия с размерами от 6 нм в гидротермальных условиях в солянокислых растворах. Порошки иридия с площадями поверхности от 1 до $46 \mathrm{~m}^{2} / 2$ синтезированы в закрытых системах восстановлением водных растворов гексахлороиридата(III) калия. При температурах от 170 до $195{ }^{\circ} \mathrm{C}$ исследованы проиессы растворения синтезированных порошков 6 растворах соляной кислоты с добавками окислителей. Получены данные о степени растворения порошков иридия в зависимости от дисперсности, температуры, времени, окислителя.

Ключевые слова: иридий, нанопорошки, гидротермальный синтез, растворение, автоклавы, температура.

Металлы платиновой группы, и в особенности иридий, в обычных условиях устойчивы к действиям минеральных кислот, однако в некоторых случаях они могут растворяться (в присутствии некоторых примесей, в дисперсном состоянии) [1]. Большое значение на растворимость платиновых металлов оказывает наличие примесей, которые, вероятно, катализируют процессы растворения. Удовлетворительной растворимостью отличаются сплавы иридия с платиной и палладием, которые растворяются в смеси соляной и азотной кислот. Однако при содержании иридия в сплаве свыше $10 \%$ его растворимость значительно уменьшается [2]. Для растворения иридия часто используют способ спекания с пероксидом бария или едким натром с последующим выщелачиванием соляной кислотой [1]. Возможно использование метода хлорирования, когда металлический иридий нагревают в атмосфере хлора в чистом виде или в смеси с хлоридом натрия [1]. Данные методы трудоемки и могут приводить к загрязнению и потерям иридия.

Современное высокопроизводительное аналитическое оборудование (атомноабсорбционная спектроскопия, атомно-эмиссионный спектральный анализ) позволяет на заключительной стадии достоверно и оперативно определять концентрации металлов. Основную трудность представляет процедура вскрытия анализируемой пробы. Пробоподготовка определяет не только продолжительность, но и точность анализа в целом. 
Перспективным методом является растворение платиновых металлов в соляной кислоте в присутствии окислителей в запаянных ампулах под давлением [2]. Применение автоклавных технологий позволяет снять кинетические затруднения, характерные для соединений металлов платиновой группы, и весьма привлекательно ввиду экологической безопасности процессов, эффективности использования реагентов, относительной простоты стандартизации условий эксперимента [3]. К сожалению, работы по автоклавному растворению металлов платиновой группы немногочисленны. В [4] разработаны методики анализа с автоклавной пробоподготовкой для высокочистых веществ: редких тугоплавких, редкоземельных, драгоценных и цветных металлов, оксидов и солей этих металлов, сплавов. Авторы [5] растворяли небольшие количества иридия нагревом в запаянной трубке с концентрированной соляной кислотой и окислителем при температурах свыше $250{ }^{\circ} \mathrm{C}$ при повышенных давлениях. Механизм растворения, по мнению авторов, обусловлен выделением свободного хлора, который окисляет иридий [5]. В работе [6] показано, что при температурах свыше $210{ }^{\circ} \mathrm{C}$ возможно растворение порошка иридия (до 97 \%) в растворах соляной кислоты при применении в качестве окислителя перекиси водорода. Однако авторами [6] не указаны структурные характеристики иридиевого порошка. В работах [7-9] показана высокая эффективность использования автоклавов для разложения платиносодержащего минерального сырья, в том числе техногенного. Использование закрытых систем позволило перевести металлы платиновой группы из твердой фазы в раствор за более короткое время при минимальном расходе реагентов по сравнению с открытыми системами $[7,8]$.

Таким образом, изучение различных условий на растворимость порошков иридия (0) весьма актуально как для разработки аналитических методов его определения, так и для процессов его выщелачивания из промпродуктов аффинажного производства. Цель настоящей работы заключалась в синтезе наноразмерных порошков иридия различной дисперсности и исследовании влияния температуры, времени, размеров частиц, окислителей на процессы их растворения.

\section{Экспериментальная часть}

$\mathrm{B}$ данной работе использовали: $\mathrm{K}_{3} \mathrm{IrCl}_{6}$ (синтезирован по методике, описанной в работе [10]); соляную кислоту - «ос.ч. 20-4»; гидразин гидрат - «х.ч»; боргидрид натрия - «х.ч»; перекись водорода 36 \%; диоксид марганца - «чда»; перманганат калия - «чда», гидроксид натрия - «Х.ч», аффинированный иридий (ГОСТ 12338-81). Синтез порошков иридия различной дисперсности проводили восстановлением водных растворов гексахлороиридата(III) калия гидразин гидратом или боргидридом натрия в закрытых системах. В автоклав помещали навеску комплексного соединения и раствор соляной кислоты, в чашечку - восстановитель, автоклав герметизировали и нагревали в воздушном термостате. После прогрева до требуемой температуры осуществляли смешение фаз включением перемешивания. Наблюдали изменение окраски (обесцвечивание) раствора в первые минуты и фиксировали образование черного порошка (5-15 мин). Полученные осадки отделяли от раствора, обрабатывали 1М соляной кислотой, промывали дистиллированной водой до отрицательной реакции на хлорид-ионы и сушили до постоянной массы в условиях вакуума при температуре менее 353 К [11]. Для определения структурных характеристик использовали комплекс физико-химических методов. Рентгено- 
фазовый анализ образцов проводили с использованием рентгеновского дифрактометра ДРОН4 (Россия) с излучением $\mathrm{Cu}-\mathrm{K} \alpha(\lambda=0,15406$ нм) в интервале углов $2 \Theta$ от 30 до 90․ Регистрация изотерм адсорбции азота для исследуемых материалов была выполнена с помощью анализатоpa ASAP-2420 (Micromeritics, USA) при 77К. Расчет текстурных характеристик осуществлялся с помощью методов ВЈН и ВЕТ. Микроскопические исследования проводили на сканирующих электронных микроскопах TM-3000 и S5500 (Hitachi, Япония), укомплектованных рентгеноспектральным анализатором.

Концентрации элементов в растворах проводили методами атомно-абсорбционной спектроскопии AAnalyst-400 (PerkinElmer, США) и масс-спектрометрии с индуктивно связанной плазмой ICP-MS 7500a (Agilent, США).

Эксперименты по растворению иридия осуществляли в кварцевых автоклавах объемом от 20 до $50 \mathrm{~cm}^{3}$ [12]. В настоящей работе для растворения иридия использовали соляную кислоту. Из ряда минеральных кислот $\mathrm{HCl}$ является наиболее часто используемой, так как позволяет перевести металл в хлоридные формы, удобные для анализа. Концентрация кислоты 6 моль/л оптимальна с точки зрения создаваемого давления паров, которое экспоненциально возрастает с увеличением температуры.

В кварцевую пробирку помещали реагенты (иридий 10 мг, окислитель), заливали 10 мл кислоты и 0,1-0,5 мл перекиси водорода, герметизировали и нагревали в термостате до заданной температуры при постоянном перемешивании в вертикальной плоскости. Конструкция автоклавов позволяет также проводить эксперименты с разделением фаз, когда твердые реагенты помещают в стаканчик, закрепленный в верхней части автоклава, а в кварцевую пробирку заливают жидкие реагенты. В данном случае смешение фаз осуществляли после прогрева системы до требуемой температуры путем включения перемешивания. В ходе процесса визуально контролировали изменение окраски раствора. После истечения заданного времени автоклав доставали, охлаждали. Раствор отфильтровывали через фильтр «синяя лента» в одноразовую пробирку для анализа.

\section{Результаты и их обсуждение}

Установлено, что восстановление боргидридом натрия солянокислых водных растворов гексахлороиридата(III) калия до металлического иридия при температурах $130{ }^{\circ} \mathrm{C}$ происходит в течение 30 мин. В случае гидразин гидрата восстановление протекает менее эффективно, на стенках автоклава образуется зеркало, восстанавливается до 70 \% иридия. Варьируя время и $\mathrm{pH}$ исходных систем, а также концентрацию $\operatorname{Ir}(\mathrm{III})$ в растворе, синтезировали ряд порошков иридия (0). Процесс восстановления иридия(III) суммарно можно описать уравнением

$$
16 \mathrm{~K}_{3} \mathrm{IrCl}_{6}+6 \mathrm{NaBH}_{4}+9 \mathrm{H}_{2} \mathrm{O}=16 \mathrm{Ir}+6 \mathrm{NaCl}+3 \mathrm{~B}_{2} \mathrm{O}_{3}+42 \mathrm{HCl}+48 \mathrm{KCl} .
$$

Рентгенофазовый анализ порошков показал присутствие пиков, характерных для фазы металлического иридия (рис. 1). На рентгенограммах проявляется уширение пиков, одной из причин которого является дисперсность материала. Согласно результатам газовой адсорбции (табл. 1) удельные поверхности порошков лежат в диапазоне от 1 до $46 \mathrm{~m}^{2} /$ г. Площади поверхности удовлетворительно коррелируют с усредненным размером частиц $\left(\mathrm{D}_{\mathrm{cp}}\right)$, определенным

$$
-328-
$$




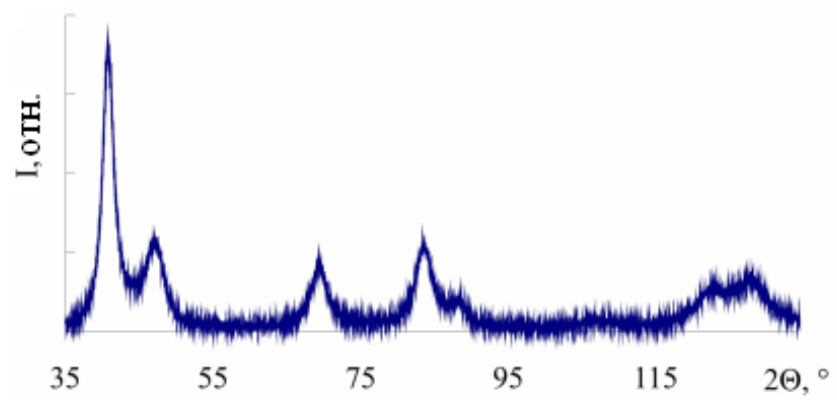

Рис. 1. Рентгенограмма иридия, $46 \mathrm{~m}^{2} / \Gamma$

Fig. 1. Fragment of XRD pattern of iridium powder, $46 \mathrm{~m}^{2} / \mathrm{g}$

Таблица. 1. Структурные характеристики порошков иридия

Table 1. Structural characteristics of iridium powders

\begin{tabular}{|c|c|c|c|}
\hline № обр & $\mathrm{S}_{\text {пов-ти }}, \mathrm{M}^{2} / \Gamma$ & $\left(\mathrm{D}_{\mathrm{cp}}\right), \mathrm{нм}$ & Описание материала \\
\hline 1 & 46 & $5-8$ & черный \\
\hline 2 & 11 & $20-30$ & черный \\
\hline 3 & 5 & $50-60$ & черный \\
\hline 4 & 1 & $200-300$ & черный \\
\hline 5 & $<0,1$ & $>1000$ & серый, компактный \\
\hline
\end{tabular}

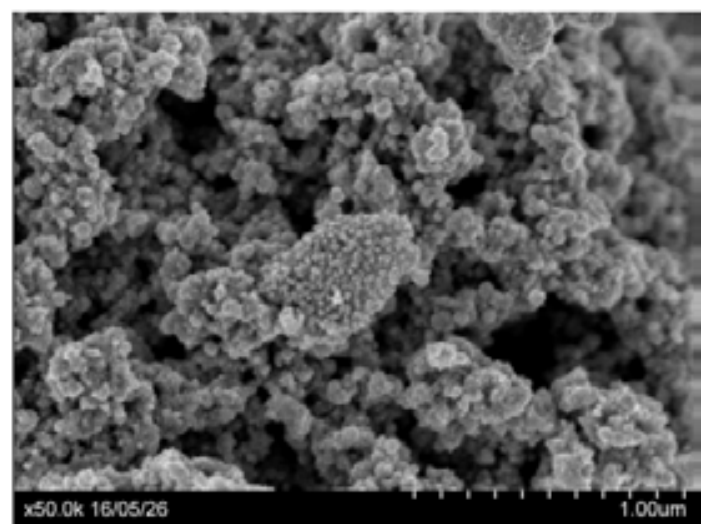

Рис. 2. СЭМ-изображение иридия, $46 \mathrm{~m}^{2} / \Gamma$

Fig. 2. SEM image of iridium particles, $46 \mathrm{~m} 2 / \mathrm{g}$

методом сканирующей электронной микроскопии (рис. 2). В настоящей работе на растворимость были исследованы следующие образцы (табл. 1).

В методиках автоклавного растворения обычно используют кислоты $\left(\mathrm{HCl}, \mathrm{HF}, \mathrm{HNO}_{3}\right.$, $\left.\mathrm{HClO}_{4}\right)$ различных концентраций или их смеси с добавками окислителей $\left(\mathrm{H}_{2} \mathrm{O}_{2}, \mathrm{KMnO}_{4}, \mathrm{NaClO}_{3}\right.$, $\mathrm{MnO}_{2}$ ) [7]. Известно, что иридий растворяется в соляной кислоте с добавлением окислителя, 
однако данный процесс кинетически заторможен и может быть реализован при повышенных температурах в закрытых системах. Точный механизм растворения иридия не установлен; вероятно, растворение связано с образованием в системе свободного хлора, который окисляет иридий. В качестве окислителей были опробованы $\mathrm{MnO}_{2}$ и $\mathrm{KMnO}_{4}$. Значительных отличий в степени растворения при использовании данных веществ обнаружено не было, поэтому в дальнейших исследованиях применяли диоксид марганца (IV). Суммарно данный процесс может быть описан уравнением

$$
\mathrm{Ir}+10 \mathrm{HCl}+2 \mathrm{MnO}_{2} \rightarrow \mathrm{H}_{2} \mathrm{IrCl}_{6}+2 \mathrm{MnCl}_{2}+4 \mathrm{H}_{2} \mathrm{O}
$$

Существенные отличия обнаружены при проведении экспериментов с добавками перекиси водорода и без нее (рис. 3). Добавление перекиси приводит к увеличению растворимости иридия. Например, за 480 мин (рис. 3) без перекиси водорода растворяется $17 \%$ иридия, а с добавлением - $23 \%$.

Значительное влияние на растворимость иридия оказывает температура: при увеличении со 170 до $195{ }^{\circ} \mathrm{C}$ степень растворения иридия существенно возрастает (рис. 4). Для иридия с удельной поверхностью $5 \mathrm{~m}^{2} / \Gamma$ удалось добиться количественного растворения за 30 ч при температуре $195^{\circ} \mathrm{C}$, в то время как при $170{ }^{\circ} \mathrm{C}$ растворяется только $15 \%$. Кинетическая кривая растворимости показывает, что в первые часы при 170 и $180{ }^{\circ} \mathrm{C}$ наблюдается наибольшее растворение иридия и далее процесс растворения при этих температурах практически не протекает. Первоначально высокая скорость растворения связана с окислением более мелких частиц. Данный факт подтвержден измерениями удельных площадей порошков до частичного растворения $\left(5,1 \mathrm{~m}^{2} / \Gamma\right)$ и после $\left(1,8 \mathrm{~m}^{2} / \Gamma\right)$.

На рис. 5 показано влияние удельной поверхности порошков иридия на растворимость при $180^{\circ} \mathrm{C}$ в течение 240 мин. С уменьшением удельной поверхности снижается растворимость порошков: компактный иридий в данных условиях практически не растворим $(<0,1 \%)$.

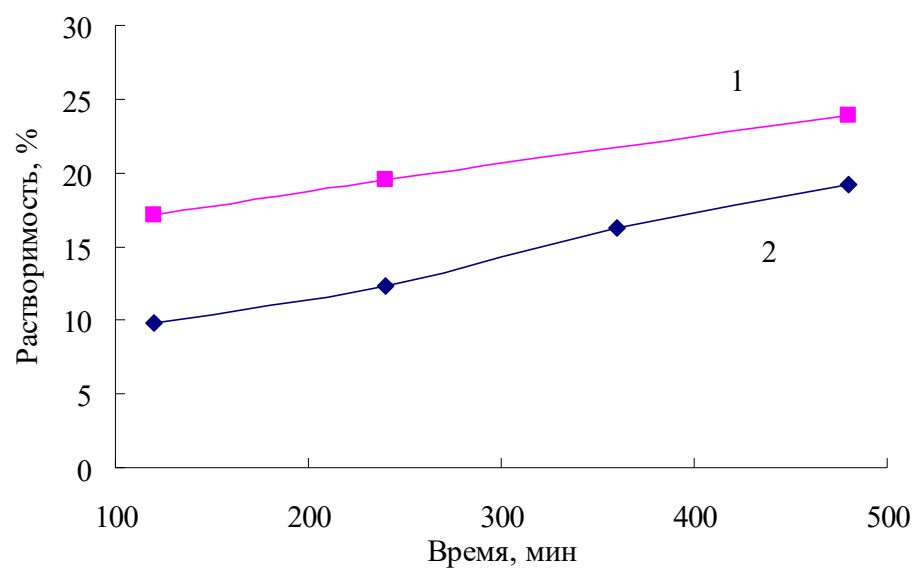

Рис. 3. Кинетические зависимости растворения иридия (образец № 3 , табл. 1) $190{ }^{\circ} \mathrm{C}, 6 \mathrm{M} \mathrm{HCl}, \mathrm{MnO}_{2}$ : 1 - с добавкой перекиси водорода и 2 - без перекиси водорода

Fig. 3. Kinetic dependences of iridium dissolution (sample № 3, Table 1) $190{ }^{\circ} \mathrm{C}, 6 \mathrm{M} \mathrm{HCl}, \mathrm{MnO}_{2}$ : 1 - with the addition of hydrogen peroxide; 2 - without hydrogen peroxide 


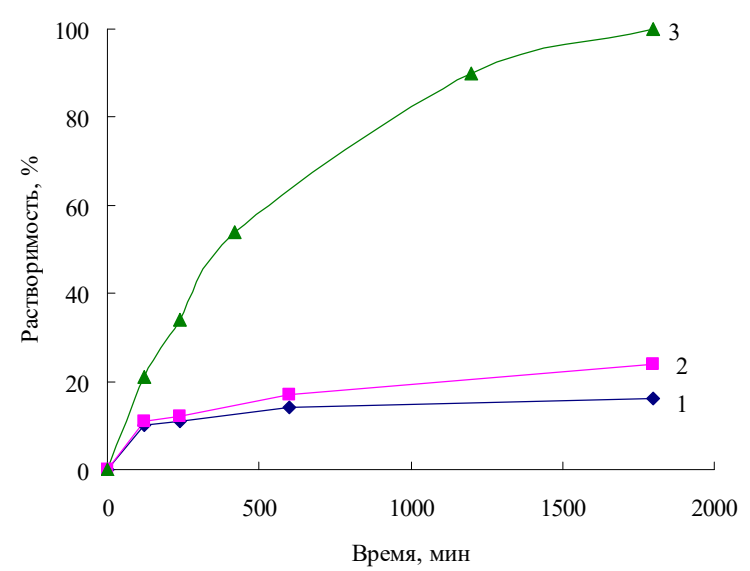

Рис. 4. Влияние температуры и продолжительности процесса на растворимость иридия $\left(5 \mathrm{M}^{2} / \Gamma\right): 1-170{ }^{\circ} \mathrm{C}$; $2-180{ }^{\circ} \mathrm{C} ; 3-195{ }^{\circ} \mathrm{C}$

Fig. 4. Effect of temperature and time of the process on the solubility of iridium $\left(5 \mathrm{~m}^{2} / \mathrm{g}\right): 1-170{ }^{\circ} \mathrm{C} ; 2-180{ }^{\circ} \mathrm{C}$; $3-195^{\circ} \mathrm{C}$

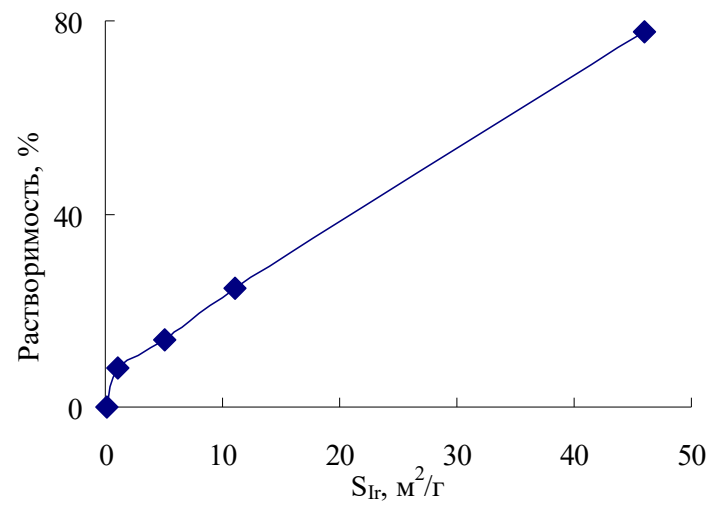

Рис. 5. Зависимость степени растворения порошков иридия (0) от дисперсности: 240 мин, $180{ }^{\circ} \mathrm{C}, 6 \mathrm{M} \mathrm{HCl}$, $\mathrm{MnO}_{2}$

Fig. 5. Dependence of iridium dissolution (0) vs powder dispersity: $240 \mathrm{~min}, 180{ }^{\circ} \mathrm{C}, 6 \mathrm{M} \mathrm{HCl}, \mathrm{MnO}_{2}$

\section{Заключение}

Установлено, что на растворимость иридия оказывает влияние температура, время процесса, присутствие перекиси водорода, дисперсность металла. Процесс растворения протекает крайне медленно даже при достаточно высокой дисперсности иридия. Наиболее заметно процесс растворения дисперсных порошков иридия протекает при температуре от $195{ }^{\circ} \mathrm{C}$ в соляной кислоте с добавками окислителей $\left(\mathrm{MnO}_{2}, \mathrm{H}_{2} \mathrm{O}_{2}\right)$.

\section{Список литературы}

1. Бимиш Ф. Аналитическая химия благородных металлов. Часть 1. 1969. М. Мир. 298 c. [Bimish F. Analiticheskaja khimija blagorodnykh metallov. Chast' 1. / 1969. M. Mir. 298 p. (In Russ.)] 
2. Гинзбург С.И. и др. Аналитическая химия платиновых металлов. 1972. М. Наука. 617 с. [Ginzburg S.I. i dr. Analiticheskaja khimija blagorodnykh metallov. 1972. M. «Nauka». 617 p. (In Russ.)]

3. Belousov O.V., Belousova N.V., Ryumin A.I., Borisov R.V. Behavior of platinum metal concentrates under autoclave conditions //Russian Journal of Applied Chemistry 2015. V. 88 (1), P. 3134.

4. Карпов Ю.А., Орлова В.А. Современные методы автоклавной пробоподготовки в химическом анализе веществ и материалов. Заводская лаборатория. Диагностика материалов. 2007. T. 73. №1. C. 4-11. [Karpov Ju.A., Orlova V.A. Sovremennye metody avtoklavnoj probopodgotovki v khimicheskom analize veshhestv i materialov. Zavodskaja laboratorija. Diagnostika materialov. 2007. 73(1), 4-11. (in Russ.)]

5. Wichers E., Schlecht W.G., Gordon C.L. Attack of refractory platiniferous materials by acid mixtures at elevated temperatures. Journal of research of the National Bureau of Standards. 1944. V. 33. P. 363-381.

6. Hodgson A.P.J., Jarvis K.E., Grimes R.W., Marsden O.J. Development of an iridium dissolution method for the evaluation of potential radiological device materials. Journal of Radioanalytical and Nuclear Chemistry. 2016. V. 307. No 3. P. 2181-2186.

7. Белоусов О.В., Дорохова Л.И., Чмышкова Т.И., Жижаев А.М. Автоклавное окислительное вскрытие геологических проб золотосодержащих руд. Цветные металль 2005. № 3. С. 13-15. [Belousov O.V., Dorokhova L.I., Chmyshkova T.I., Zhizhaev A.M. Avtoklavnoe okislitel'noe vskrytie geologicheskikh prob zolotosoderzhashhikh rud. Cvetnyemetally 2005. 3, p. 13-15. (In Russ.)]

8. Белоусов О.В., Калякин С.Н., Твердохлебов В.П., Исакова В.Г., Гризан Н.В. Применение методов автоклавного растворения при исследовании катализаторов нефтепереработки. Катализ в промышленности. 2017. Т. 17. № 1. C. 46-50. [Belousov O.V., Kalyakin S.N., Tverdokhlebov V.P., Isakova V.G., Grizan N.V. Application of Methods of Autoclave Dissolution for Studying Oil Refining Catalysts. Kataliz v promyshlennosti. 2017; 17(1): 46-50. (In Russ.)]

9. Belousov O.V., Belousova N.V., Ryumin A.I., Borisov R.V. Refining of platinum-palladium concentrate under hydrothermal. Russian Journal of Applied Chemistry 2015. V. 88 (6), P. 1075-1078.

10. Синтез комплексных соединений металлов платиновой группы: справочник / под ред. Черняева И.И. 1964. Л.: Наука. 340 с. [Sintez kompleksnykh soyedineniy metallov platinovoy gruppy: Spravochnik pod red . I.I. Chernyayeva. 1964. L .: Nauka. 340 p. (In Russ.)]

11. Borisov R.V., Belousov O.V., Irtyugo L.A. Thermostimulated transformations of highly disperse powders of platinum group metals in an argon atmosphere. Russian Journal of Physical Chemistry A. 2014. V. 88. No 10. P. 1732-1738.

12. Борисов Р.В., Белоусов О.В. Получение наноразмерных частиц палладия на углеродных носителях в автоклавных условиях. Вестник Кемеровского государственного университета. 2014. Т 3. Вып. 59. С. 174-177. [Borisov R.V., Belousov O.V. Preparation of palladium nanoparticles on carbon substrates in autoclave conditions. The bulletin of Kuz-STU. 2014. 59(3), 174-177 (In Russ.)]. 